\section{THE SALICYLATE TREATMENT OF ACUTE RHEUMATISM. ${ }^{1}$}

BY W. H. BROADBENT, M.D., F.R.C.P., PHYSICIAN TO ST. MaRY'S Hospital.

IT remains for me to give the statistics-comparatively small statistics-which I have to lay before the Society, and then briefly to sum up what seems to me to have been the general outcome of this most interesting and valuable discussion.

The first case which I treated by salicylic acid was in February, 1876-one of the earliest cases, I think, next to those of Dr. Maclagan, in this country. I have from that time records of ninety cases treated by salicyl compounds, mainly salicylate of soda. I am unable to give the precise duration of pain and fever, as has been done by many of my predecessors in this discussion. I can only say that my experience coincides closely-I may say, exactly - with that of many observers who maintain that after the administration of salicylic compounds in acute rheumatism the pain subsides with extreme rapidity, and the fever also; and that, whatever the ultimate results may be, the immediate relief afforded is most striking.

The arerage duration of stay in hospital in these cases was amongst the males 32.2 days, and amongst the females

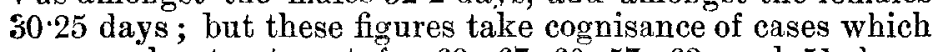
were under treatment for $69,67,60,57,63$, and 51 days, and of a few similar periods where the salicylate was given for only a short time at the very commencement of the attack. In my experience, where the salicylate fails to influence the disease at once, there is very little to be boped from a continuance of its administration. The cases of relapse have been fifteen in number, and in four of these fifteen there were two relapses.

As regards cardiac complications I cannot contribute very much information. Taking all my cases together there would be about the usual proportion of such complications, but very early in my experience I recognised the fact that salicylic acid or the salicyl compounds had no influence whatever upon the course certainly of nericarditis, and a very small influence upon the course of endocarditis, and that not only was the lesion itself-the inflammatory cardiac lesion-unaffected, but when one had to deal with cardiac inflammations the fever failed to subside under the salicylates. Indeed, the only case of hyperpyrexia I have seen under the influence of salicylic acid was in a patient with pericarditis; that condition was recognised when the temperature was $107^{\circ} \mathrm{F}$, , the cold bath was then resorted to, and the patient's life was saved. The moment $I$ recognise any cardiac inflammation I discontinue the administration of salicylic compounds, and several times it has happened to me, on coming into the hospital, to find that the salicylates have been prescribed in a case of acute rheumatism, and to recognise from the persistence of a comsparatively high temperature in spite of the drag, the imminence and the probable existence of pericarditis or endocarditis, which had not been revealed by any physical sign, and to have that surmise confirmed. I ought to add that in endocarditis the resistance to the effects on temperature of the salicyl compounds is not so marked as in pericarditis. I should think, judging from my own experience, that in many of the cases in which the temperature persists after the alleviation of pain this is due really to the existence of endocarditis, which of course has been recognised, though it has not been shown in the tables laid before us. With regard to cardiac weakness left behind as the result of the admivistration of salicylic compounds, that is unknown to me as a permanent affection, but what I have seen more than once has been that, when a very high temperature has rapidly gone down under the influence of salicylic compounds, the pulse has not only been infrequent but very weak. This, however, is exactly what happens after the defervescence of relapsing fever, in which it is almost constant, and what we sometimes see in the defervescence after a crisis in pneumonia. I attribute, therefore, the temporary weakness of the heart's action

1 Concluding remarks at the discussion at the Medical Society of London, Jan. 16th, 1882 . not to the effect of the salicylates, but to the sudden aud rapid fall of temperature. Very little has been said as to the mode of administration of the remedy, which is, in my opinion, a matter of considerable importance, The quantity ot salicylic acid I have usually given is twenty grains, in combination with soda, every hour for six hours, and this is repeated on the second day. The further administration of the salicylic compounds has been the same dose, perhaps, three times a day, or, if the temperature is not absolutely gone down, as is the rule, this dose is given four times per diem for some days afterwards.

Notwithstauding this rapid administration of the drug, which I myself am decidedly of opinion is the best, $I$ have seen comparatively few really unfavourable symptoms attributable to its action. In only three cases was there serious delirium, in one there was strangeness of manner and sullen. ness, and in three giddiness, and in five decided deafness. Where there have been very marked toxic symptoms I am very greatly inclined to believe, indeed it has been demon. strated in many cases, that there has been some impurity in the drug. I think that the Society is greatly indebted to Dr. Fowler of Cambridge for his kindness in coming here to state the experience he has had in the use of the drug prepared directly from wintergreen, and not from sources whence come carbolic acid and other similar compounds which might have dangerous effects.

This, then, is what I have to contribute as the result of my personal experience, and I have now, further, only to congratulate the society on the extremely interesting and valuable information which has been placed before it. I have not been able to determine exactly numbers upon which the conclusions have been founded, because the tabular statements have overlapped in some degree, but certainly more than a thousand cases of rheumatic fever treated by salicyl compounds have been under the consideration of the different speakers who have brought the matter before the Society, and any one of these papers would have gone far to place the salicylic acid treatment of rheumatic fever in its true light. If facts can settle a question, then I con. sider that the value of the salicylic treatment of rleumatic fever may be considered as settled. We have, I think, had the subject statistically treated from every possible point of view, Each evening the walls of this room have been covered with elaborate tables, which have conveyed informa. tion of extreme importance and interest. In all respects singularly good tortune has attended the efforts of the Society to deal with this question, not the least of our grounds for self-gratulation being that the introduction of the subject was undertaken by Dr. Fagge. It was not only by the large array of facts which he set before us, and by the lucid manner in which the conclusions deducible from these facts were brought out, but also by his preliminary remarks as to the method of dealing with the subject, and as to the difficulties surrounding it, that he laid us under special obligation. Every subsequent paper must, I think, really gain in value from being read in the light of those prelininary remarks.

Witb respect to otber papers, we have had, on the one hand, the personal experience of Dr. de Havilland Hall, of Dr. Coupland, and this evening of Dr. Douglas Powell; on the other hand, the statistics drawn from hospital records by Dr. Isambard Owen, Dr. Warren, and Dr. Donald Hood. Now, however an individual might have been led away by preconceived notions, there is no reason why those who follow and who look ouly at the results should be so led away, and it is remarkable how the consensus of opinion tends in one direction; and I hold that the questions which I ventured to hope might receive some sort of answer by means of this discussion are really effectually answered, although perhaps no one has specially addressed himself to them. The answers may not have been direct, but they have been for that very reason all the more conclusive. I think we may say definitely that by means of salicylic compounds the duration of the pain and fever in rheumatism is unmistakably lessened; and, even if the stay in hospital is not materially shortened, certainly the suffering is very greatly diminished. With regard to relapses, perhaps we may say that they seem to be more common under the new than under the old methods of treatment; still I am quite sure that the explanation of this is to be found in the rapidity with which all the acute symptoms subside under the administration of salicylates. You cannot in these circumstances get the patients to be so careful of themselves as when they have gone through the terrible sufferings of an 
unalleviated attack of acute rheumatism. You cannot make sure that even the nurses will be so careful as they should be. Over and over a rain I have gone to the bedside of a patient, who has just come out of acute rheumatism, and have found a stream of air pouring down up:n the bed, in consequence of the zeal of sisters and nurses for ventilation; and to this fact $I$ am quite certain that many relapses are due. Dr. Poweil's remark that the relapses are "a question of account," is, I believe, to some extent a perfectly true one ; but in a considerable number of cases we tind the temperature going down, and the pain departing, at the end of a very few days, and once for all. Whether we date the cure from the time of the subsidence of pain and high temperature, or later on, is of no great consequence, and I think Dr. Powell himself, while hesitating to say th it salicylates cure rheumatism, his brought forward the strongest evidence that he possibly could in proof of this point. The cases of acute catarrhal pneumonia and cerebro-spinal meningitis which have been "cured"-and I think we may use the term-I consider exemplify and emphasise the actual cure of an acute rheumatic attack, also of the positive antagonising of the rheumatic disease, be the cause poison in the blood, a condition of the nervous system, or what it may. I am not aware that there have been brought forward any illustrations of bad effects which at all neutralise the good results that we have seen. I should like to ask Dr. Powell-I am afraid we shall not be able to call upon him again in this discussion, but when, as is hoped, these cases are published in extenso-to answer the question whether in his cases of hyperpy rexia there were not cardiac complications. These make an extraordinary difference in the action of salicylic compounds. It is within my own experience that the temperature in some cases not only does not fall, but tends to rise, when we have acute pericarditis treated with salicylic compounds.

A question which we have not been able to resolveindeed I do not know that the material exists for its determination -is the relative ad vantages of the different salicyl compounds. It seems to me that the vatural salicylic acid, as being less liable to contamination than the samples made from coxl-tar compounds, is preferable to the latter; and it is a matter for inquiry which no doubt will be submitted to the test of experience, and which certainly I for one shall endeavour to elucidate, whether salicin has the advantages over salicylic acid claimed for it, and possibly with good reason, by Dr. Maclagan. I have not yet alluded to Dr. Maclagan's valuable contributions to the discussion, in which we have his own personal experience and the general statement of results of the salicyl treatment from a large number of hospitals.

Turning now to another part of the subject, I myself do notin spite of those most interesting, and of course accurate, tables which have been brought before us by Dr. Gilhart Smitb,believe that the salicylates increase the frequency of heart disease; on the contrary, I quite coincide with the hope and anticipation expressed by Dr. Fagge, in the early part of the discussion, that when salicylates are brought to bear upon the fever in the first days of its existence we shall see a notable diminution in the heart disease; for in my own ex. perience, during the whole administration of salicylates, it has been exceedingly rare to see heart disease springing up. One question there is which has been very little dwelt upon-viz., the modus operandi of the remedy. I dislike very much the terms "anti-rheumatic" and "anti-pyretic," and indeed all terms beginning with "anti " but in my earlier remarks I was compelled to use them for the sake of brevity. A matter of great moment, however, is the way in which salicylic compounds act-whether they bring down the pain because they abate the fever, or whether they bring down the fever because they destroy the cause of the pain. My own very strong opinion is, that it is not merely as dealing with fever that the salicylic compounds act. They have little influence over pyrexia due to other causes than rheumatism. In relieving the fever of typhoid, for example, they are not to be compared with quinine; and, indeed, my own experience of the salicylates in enteric fever has not been favourable. It appears to me that in some way or other the salicyl compounds antagonise the disease rheumatism, whatever it may be.

I will not enter now upon the discussion of the various hypotheses which have been advanced as to the nature and cause of rheumatism - that of Dr. Maclagan for instance, or that of Dr. Latham. I must, however, express my dissent from Dr. Maclagan's theory, of its malarial origin and bacterial cause, which does not seem to fit in with all the facts in the hi-toiy of acute rheumatisu. Again, I cannot accept the existence of the special chemical coordinating ceutse of Dr. Latham, and therefore I am unable to receive his conclusions drawn therefrom. In sayiug this I do not mean to insply that I deny to the nerrous sy stem any share in the production of rheumatic fever. I object simply to the establishment of another of those centres which are postulated for auything of which we want an explanation.

I shall be very glad to hear tbat which we need for the conclusion of this meeting-riz, the experience of general practitioner, of which we cannot have too much. It is not likely that this can, ia respect of multiplicity of facts, com. pete with the experience brought from hospitals ; but it is, nevertheless, of very gre at value, and must ad I considerably to the interest of the discussiun, which on this account 1 should be glad to lengthen for about half an hour. I shall finally have only to ask Dr. Hillton Fagge to resly on the whule question.

\section{ON A CASE OF HERNIA OF LUNG THROUGH THE DIAPHRAGM.}

BY E. CLIFFORD BEALE, M.B., M.R.C P.,

ASSISTANT-PHYSICIAN TO THE CITY OF LONDON HOSPITAL FOR DISEASES OF THE CHEST, VICTORIA-PARK ; PHYSICIAN TO THE GREAT NORTHERN HOSPITAL.

CASss of ruptured diaphragm followed by herniæe of abdominal viscera into the thoracic cavity are by no means rare. All the text-books of the present day refer to them and the Transactions of our own and foreign Pathological Societies contain numerous detailed accounts of special cases. I have searched in vain, however, in numerous Transactions, records, and reference-books for any account of the opposite condition to this-viz., rupture followed by hernia of thoracic contents into the cavity of the abdomen. The details of the following case therefore become worthy of consideration as illustrative of a very rare and interesting patbological condition, and may, in addition, serve to illustrate some points in the general pathology of diaphragmatic herniæ.

W. $\mathrm{P} \longrightarrow$, aged twenty-two, was admitted into the Great Northern Hospital on Aug. 11th, 1881, in a state of extreme shock, having been severely injured by his own cart, from which he had fallen. One of the wheels had struck him on the right side of the abdomen and had pushed him along the ground, squeezing him severely, but not going completely over him. His condition on admission to the hospital was such that his recovery seemed impossible, and hence no detailed physical examination was at first attempted. His friends stated that his previous health had been good, but that he had always been remarkably thin. Gradually recovering from the shock, he complained of pain in the right side of the abdomen; his breathing, which had always been rapid, was then noticed to be almost entirely thoracic. He had no sickness, cough, or hamoptysis. Temperature $99^{\circ}$; pulse 108; respiration 36 . Bowels confined. There was no external evidence of injury to be found. On the third day the bowels were freely opened by enema, there was less local pain, but the respiration continued wholly thoracic, thirtythree per minute. On the fifth day slight signs of peritonitis were observed, and there was some jaundice, but the bowels continued to act naturally. The character of the respiration remained unaltered. Physical examination of the chest showed marked dulness at the base of the right lung, with some crepitation and rhonchus on both sides. Cough followed, with slight hæmnptysis, and subseqeuntly the sputa became thick, puruleut, and often nummulated suggesting phthisical destruction of the lung. He continued in much the same state during September, the temperature chart throughout showing a regular eveving rise to $102^{\circ}$ or $103^{\circ}$, with a day temperature of $986^{\circ}$ to $100^{\circ}$

Exrly in Oetober his condition improved somewhat, and he was allowed to get up occasionally, but shortly afterwards he had several attacks of sickness and diarrhoea ; the breathing was less thoracic than hefore; the congh continued, and his strength began rapidly to fail. The right side of his chest was found almost absolutely dull to percussion behind, and bronchial breathing and other signs of con- 